\title{
The Value of CCTV Surveillance Cameras as an Investigative Tool: An Empirical Analysis
}

\author{
Matthew P. J. Ashby ${ }^{1}$
}

Published online: 21 April 2017

(C) The Author(s) 2017. This article is an open access publication

\begin{abstract}
There has been extensive research on the value of closed-circuit television (CCTV) for preventing crime, but little on its value as an investigative tool. This study sought to establish how often CCTV provides useful evidence and how this is affected by circumstances, analysing 251,195 crimes recorded by British Transport Police that occurred on the British railway network between 2011 and 2015. CCTV was available to investigators in $45 \%$ of cases and judged to be useful in $29 \%$ ( $65 \%$ of cases in which it was available). Useful CCTV was associated with significantly increased chances of crimes being solved for all crime types except drugs/weapons possession and fraud. Images were more likely to be available for more-serious crimes, and less likely to be available for cases occurring at unknown times or in certain types of locations. Although this research was limited to offences on railways, it appears that CCTV is a powerful investigative tool for many types of crime. The usefulness of CCTV is limited by several factors, most notably the number of public areas not covered. Several recommendations for increasing the usefulness of CCTV are discussed.
\end{abstract}

Keywords Closed-circuit television · Surveillance camera · Criminal investigation · Policing

\section{Introduction}

Closed-circuit television (CCTV) surveillance cameras are widely used in policing, but that use is controversial. The United Kingdom (UK) government has described CCTV as "vital" for detecting offenders (Porter 2016), while the Washington, DC, Metropolitan Police Department (2007, p 2) argued that it is often "invaluable to police investigations".

Matthew P. J. Ashby

matthew.ashby@ntu.ac.uk

1 Nottingham Trent University, Burton Street, Nottingham NG1 4BU, UK 
On the other side of the debate, the campaign group (Liberty 2016) argued that extensive use of CCTV "poses a threat to our way of life" and that "widespread visual surveillance may well have a chilling effect on free speech and activity". Similarly, the American Civil Liberties Union claimed that public CCTV surveillance creates "an almost Orwellian potential for surveillance and virtually invite[s] abuse" (Steinhardt 1999).

In the academic literature, there has been discussion of how CCTV fits into broader conceptions of surveillance (Hier 2004; Koskela 2003) and the extent to which it increases or changes the nature of state or corporate power over citizens (Fyfe and Bannister 1996; Norris and Armstrong 1998). Concerns have been raised that CCTV surveillance may restrict the diversity and vibrancy of life in public spaces (Bannister et al. 1998), or contribute to the exclusion of some groups in society (Reeve 1998). There has also been political debate about the proper balance between ensuring the effectiveness of CCTV and protecting the privacy of citizens (Sheldon 2011).

Although the debate about CCTV has been both long lasting and wide ranging, empirical evidence on the topic has so-far not covered all of its aspects. This article will attempt to provide evidence to inform one area of this debate about which evidence is currently limited: the extent to which CCTV is valuable for criminal investigations. The next section contains a review of the existing literature, followed by an explanation of the mechanisms that may influence the effectiveness of surveillance cameras in investigations. The following section will describe the data used in this study, derived from police reports of crimes on the railway network of Great Britain. The results section will describe how often CCTV has been useful in crime investigations, and in what circumstances. Finally, the implications of these results for policy makers and practitioners will be discussed.

\section{Existing Literature}

Given the controversial nature of CCTV, surprisingly little is known about how it is used and how effective it is in achieving many stated aims. CCTV has several potential applications for public safety, and has been deployed with the intention variously of preventing crime, detecting offences, improving the response to emergencies, assisting in the management of places and reducing public fear of crime (Ratcliffe 2011, p 15). CCTV can also be used for purposes not related to public safety, such as monitoring transport-passenger flows and investigating complaints against facility staff (National Rail CCTV Steering Group 2010, p 7).

Of these potential applications, almost all research attention to date has concentrated on the use of CCTV to prevent crime (Honovich 2008). Early studies by Mayhew et al. (1979) and Webb and Laycock (1992) suggested that CCTV was effective at reducing robberies at London Underground stations, although the evaluation methods used had some limitations. Since then, the subject has received substantial research attention with mixed empirical results. For example, several evaluations have found CCTV to be effective at reducing thefts in car parks (Poyner and Webb 1987; Tilley 1993) but others have shown it to have little or no impact on crime in residential areas (Gill and Spriggs 2005). A systematic review by Welsh and Farrington (2008) of 41 studies concluded that CCTV is effective at preventing some types of crime in some circumstances, but that the evidence suggests it has a morelimited impact than its widespread deployment may suggest.

In contrast to the extensive literature on the value of CCTV for crime prevention, there is little research on how useful cameras are for other purposes. Ditton and Short (1998) found that in the 2 years after the installation of a CCTV scheme in a Scottish town, the proportion of crimes that were solved by police increased from 50 to $58 \%$, with some offences 
showing larger increases than others. However, no information was given about whether these changes were statistically significant, and rates were only provided for some types of crime (the primary focus of the study was on crime prevention). In Australia, Wells et al. (2006) found that monitored CCTV in two suburbs led to the early arrest of a small number of offenders at the scenes of crimes, but did not look at whether recordings were useful in the subsequent investigations.

Limited evidence can be found in research on solvability factors: the features of an offence that determine the likelihood of the case being solved. Paine (2012) found CCTV to not be associated with higher detection rates for residential burglary. For non-residential burglary, Coupe and Kaur (2005) found that CCTV being installed in a building was associated with double the rate of detections compared to other buildings, driven by the increased availability of suspect descriptions. Since this study used data from the year 2000, it is possible that subsequent developments in technology may have influenced the effectiveness of CCTV in solving this type of crime. For example, modern cameras are likely to provide higher-resolution images, and digital (as compared to tape-based) storage allows images to be retained for longer (Taylor and Gill 2014). Existing research on solvability factors is limited because it is largely focused on the investigation of a single crime type (burglary).

In the context of this limited academic evidence, several organisations have produced reports on the topic of the value of CCTV for investigation, some of dubious quality. For example, Davenport (2007) summarised an unpublished report by the Liberal Democrat political party which concluded that CCTV cameras were ineffective simply because London boroughs with more cameras did not have a higher all-crime detection rate. The group appeared to have made no attempt to control for confounding variables or for different types of crime. Despite the poor quality of the analysis, this report has subsequently been cited in the media (e.g. by Bates 2008) as proof that CCTV is ineffective in investigations.

Journalists have also carried out their own analyses. Staff from The Scotsman (2008) newspaper reported that in a 4-year period CCTV cameras in Scotland had observed more than 200,000 incidents, with responding police officers making arrests in $14 \%$ of cases. However, no details were given on whether those arrests led to charges, whether further suspects were identified later or how the headline statistic varied in different circumstances or for different types of crime. In San Francisco, journalists found that cameras had given detectives new avenues of investigation in seven of 33 violent felonies committed in a crime hotspot over a 2-year period (Bulwa and Stannard 2007). Meanwhile the London Borough of Hackney (2016) reported that over a 12-year period the use of CCTV had been associated with more than 27,000 arrests, although it gave no further details. Edwards (2009) reported that CCTV evidence was gathered in 86 of 90 murder investigations and was judged by senior police officers to have been valuable in 65 of those cases.

There appears to be some disagreement within the police service as to how effective CCTV cameras are in criminal investigations. Several news outlets summarised a report from the London Metropolitan Police Service (MPS) that appeared to be highly critical of its usefulness. Bowcott (2008) reported that "only 3\% of street robberies in London were solved using CCTV images", although other articles reported that the 3\% statistic applied to all crime (e.g. Johnson 2008). In another article based on the same report, Edwards (2008) wrote that "up to 80 per cent of CCTV footage seized by police is of such poor quality that it is almost worthless for detecting crimes". Hickley (2009) quoted a police spokesperson as saying that "in 2008 less than 1,000 crimes were solved using CCTV despite there being in excess of one million cameras in London". However, to the present author's knowledge, the report itself remains unpublished and no information is available on the methods used, nor any more details of the conclusions. 
In contrast, the majority of British officers surveyed by Levesley and Martin (2005) believed that CCTV was a useful investigative tool. A report on the value of CCTV commissioned by Dyfed-Powys Police in Wales argued that cameras were valuable in the detection of crime, citing the opinions of police investigators and local prosecutors. However, the report also recommended that live-monitoring of CCTV cease because it was ineffective at preventing crime or improving the initial response to incidents (Instrom Security Consultants 2014). Several municipalities in Britain have decreased their investment in CCTV in response to recent budget cuts (Merrick and Duggan 2013).

Overall, little appears to be known about how the usefulness of CCTV for investigation varies across crime types or circumstances, which is likely to be important in any attempts to make CCTV more useful. The present exploratory study attempted to provide some evidence in these areas.

\section{How Might CCTV Help Crime Investigations?}

Before turning to the research questions addressed in this study, it is necessary to consider exactly how CCTV might provide useful evidence in a criminal investigation.

A criminal investigation can be thought of as a series of questions: who was involved in an incident, where did it happen, what happened, when did it happen, why did it happen and how were any offences committed, known as the ' $5 \mathrm{WH}$ ' investigation model (Cook et al. 2016; Stelfox 2009). CCTV may be useful in answering at least two of these questions: what happened and who was involved (La Vigne et al. 2011).

A good-quality recording could potentially allow investigators to watch an entire incident unfold in detail, providing information about the sequence of events, the methods used and the entry and exit routes taken by the offender. Even if this is not possible, CCTV may be useful in corroborating or refuting other evidence of what happened, such as witness testimony (College of Policing 2014). Recordings may also provide information that investigators can use to contextualise other evidence (Levesley and Martin 2005).

CCTV may assist in identifying who was involved in a crime either directly, as when a suspect is recognised by someone viewing the recording, or indirectly, such as when the recording shows a suspect touching a surface from which police are then able to recover forensic evidence (Association of Chief Police Officers 2011). Images can also be used to identify potential witnesses (La Vigne et al. 2011, p 27). CCTV may be less useful in answering some of the other $5 \mathrm{WH}$ questions. For example, even a good-quality recording may shed little light on why a crime was committed.

In order for CCTV to be useful in answering investigative questions, certain circumstances are required. There are few legal restrictions on the ability of police officers to use CCTV recordings of public places during investigations. In the UK, for example, operators of camera systems can provide recordings to the police without a warrant (Information Commissioner's Office 2015). In the United States (US) a similar system operates, as long as the recording is of a place in which people do not have a reasonable expectation of privacy (Chace 2001). As such, the limiting factors on the use of CCTV are likely to take other forms.

Figure 1 summarises the process by which these circumstances may come about, broken down into three stages. In the first stage, CCTV evidence is not available, either because the police have not taken steps to obtain it or because no recording exists for technical reasons. In the second stage, a CCTV recording is available but-perhaps because of the recording quality - is not useful to the investigation. In the final stage, a recording is both available and useful to the investigation. 


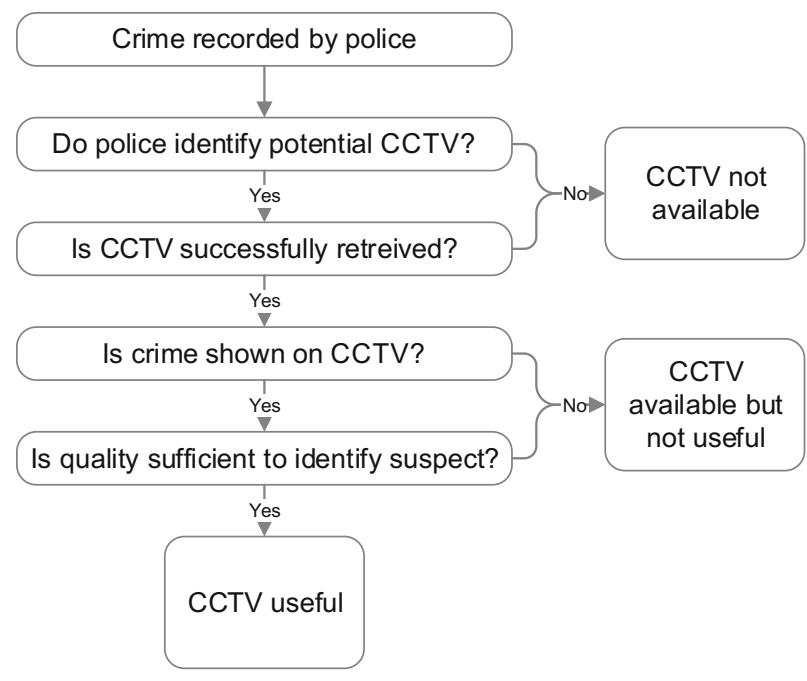

Fig. 1 The process by which CCTV can be available and useful to an investigation

The present study aimed to explore the usefulness of CCTV for crime investigation by examining the stages in this process. Specifically, two research questions were addressed:

1. How often do CCTV cameras provide useful evidence in criminal investigations, and how does this vary for different types of crime?

2. In what circumstances is CCTV most likely to be useful in criminal investigations?

It might be thought that CCTV is useful in a case only if it leads to a suspect being convicted. However, this approach presents at least two problems. Firstly, it would require a potentially unreliable counterfactual test of the weight of evidence that would have been available in a particular case in the absence of CCTV recordings. Secondly, it ignores the potential value of video recordings in allowing officers to eliminate a suspect from their enquiries, or to identify where a person has made a false report of crime.

\section{Data and Methods}

Answering the research questions addressed in this study required a source of data on the investigative value of CCTV. Although police forces collect a wide range of information about investigations for administrative and legal purposes, that information is not always stored in a way that makes it accessible for secondary analysis for research purposes. For example, case files may contain information on whether CCTV recordings were used in a particular investigation, but such files are often held either on paper or in electronic formats that are not easily searchable. As a result, research based on case files (e.g. Jordan 2004; Cockbain et al. 2011) tends to use small samples, potentially limiting its power to detect differences between crime types, circumstances and so on.

The present research takes advantage of one police force having collected data on the value of CCTV over a long period of time and stored it in an accessible format. In 2010, British Transport Police (BTP) - the specialist police force for railways in Great Britain-added two questions to the electronic form that first-line supervisors are required 
to complete at the end of a criminal investigation conducted by an officer under their command. The first question asks the supervisor whether CCTV has been useful in the investigation and the second (required only if the answer to the first question is 'no') asks the supervisor to choose from a list of reasons why CCTV has not been useful in that case. From these two questions it is possible to construct a third variable showing whether a CCTV recording existed in a case, by combining those cases where CCTV was useful with those where a recording of the location at the relevant time did exist but was not useful (for example because the images were of insufficient quality or because the wrong images were extracted from the system).

The present study used the answers to these questions together with other data about each offence, such as whether a case had been 'solved'. In common with standard practice among UK police forces, crimes were deemed to be solved if a prosecutor (or, in minor cases, a specially trained police officer) decided that there was sufficient evidence against a suspect to send the case to court. Again in common with police practice, such cases are referred to below as having been 'detected' (for further details, see Home Office 2016).

In the 5 years between January 2011 and December 2015, 251,195 notifiable crimes were recorded by BTP, or about 138 crimes each day. ${ }^{1}$ Since the data on CCTV usefulness is gathered only at the conclusion of an investigation, data for this study were extracted from the BTP crime-recording system at the beginning of March 2016 to maximise the chance of the relevant questions having been completed. Data on the usefulness of CCTV were missing in 4,768 cases ( $1.9 \%$ of the total).

The use of data from BTP was valuable for two reasons. Firstly, that force had for several years been collecting data that were not widely recorded elsewhere, providing a large sample of offences to study. Secondly, the railway network policed by BTP has a very large number of CCTV cameras. The total number of cameras on the railway network is not known, since the 25 train operating companies each operate their own camera networks and there is no central registry of cameras. However, the BTP CCTV Hub is able to monitor around 30,000 cameras at railway stations around the country (British Transport Police 2016). There are also an unknown number of cameras installed on-board trains.

The large number of cameras means that CCTV will cover the sites of a substantial proportion of recorded crimes. This helps to deal with a potential limitation of the studies discussed above, which is that only a few of the offences reported to those forces are likely to have occurred close to a CCTV camera. This in turn would make it more difficult to answer the second research question.

While the availability of data from BTP made this study possible, the use of data from a specialist police force may limit the generalisability of the results. The mix of crimes investigated by BTP is likely to be different from that seen by local police forces.

Another limitation of this data source is that in cases where supervisors identified that CCTV had been useful in an investigation, it was not possible to identify in what way it had been useful. This is a limitation of the data collection, which in turn is likely to reflect a focus within the police on improving CCTV usefulness by focusing on the reasons why recordings were sometimes not useful. It is likely that supervisors classified cases with reasonable consistency, since the second question described above asked them to pick from a

\footnotetext{
${ }^{1}$ In England and Wales, police forces are required to notify the Home Office of how many crimes occur of each type. However, very minor offences - such as failing to stop at a red traffic light or travelling on a train without a ticket-are excluded from this requirement. All other offences are included and so are referred to as 'notifiable' offences. For further details, see Home Office (2011). Crime statistics and almost all research on crime in England and Wales are based on notifiable-crime data.
} 
list of reasons (shown in Table 1) why recordings were not useful. Consistency is also likely to have been maintained by the questions asked of supervisors being constant over time. Nevertheless, it is not possible to be sure that supervisors categorised cases with complete consistency. Neither can the possibility of bias be excluded, although the author is aware of no obvious sources of bias.

The data did not distinguish between different types of CCTV. Systems can vary from extensive high-definition networks to single cameras that produce grainy images (Gill and Spriggs 2005; Taylor and Gill 2014). It is therefore likely that the effectiveness of systems will vary. Information about system type was not recorded in the BTP data and so it was not possible to explore these distinctions. However, there may be less variation in systems on railways compared to systems in other environments, because there are industry standards for rail CCTV networks (National Rail CCTV Steering Group 2010).

Despite these limitations, to the author's knowledge the sample used here represents the best-available large-scale dataset on the value of CCTV for investigating crime. Moredetailed data could have been collected for a smaller sample of crimes (for example by interviewing investigators or reviewing case files), but it would have been impractical to do this for a large-enough sample to allow analysis of different crime types and crimes occurring in different circumstances.

\section{Results}

\section{How often is CCTV Useful?}

Using the distinction between availability and usefulness shown in Fig. 1, CCTV was available in the investigation of 111,608 offences in the 5 years between 2011 and 2015$45.3 \%$ of all crimes recorded by BTP. CCTV was classified as being useful in 72,390 investigations-29.4\% of all recorded crimes and $64.9 \%$ of crimes for which CCTV was available. Camera recordings were, for example, useful in the investigation of 1,223 assaults causing serious injury, 4,120 assaults causing minor injury, 1,365 personal robberies and 2,810 sexual offences. Table 1 provides further details.

Figure 2 shows the proportion of offences of different types for which CCTV was available and, within that, the proportion for which it was useful. There are large variations across crime types, with recordings being useful in $62.2 \%$ of robbery investigations but only

Table 1 Reasons why CCTV was or was not useful

\begin{tabular}{lrr}
\hline Reason & \multicolumn{1}{c}{ Cases } & \multicolumn{1}{c}{$\%$} \\
\hline CCTV not available and therefore not useful & 134,819 & 54.7 \\
incident location not covered by CCTV & 72,042 & 29.2 \\
recording not requested by officers & 49,647 & 20.1 \\
CCTV system faulty & 5,891 & 2.4 \\
recording over-written before it was retrieved & 7,239 & 2.9 \\
CCTV available but not useful & 39,218 & 15.9 \\
recording viewed but incident not shown & 25,987 & 10.5 \\
recording viewed but images of insufficient quality & 12,055 & 4.9 \\
wrong images requested or retrieved & 1,176 & 0.5 \\
CCTV useful & 72,390 & 29.4 \\
\hline
\end{tabular}




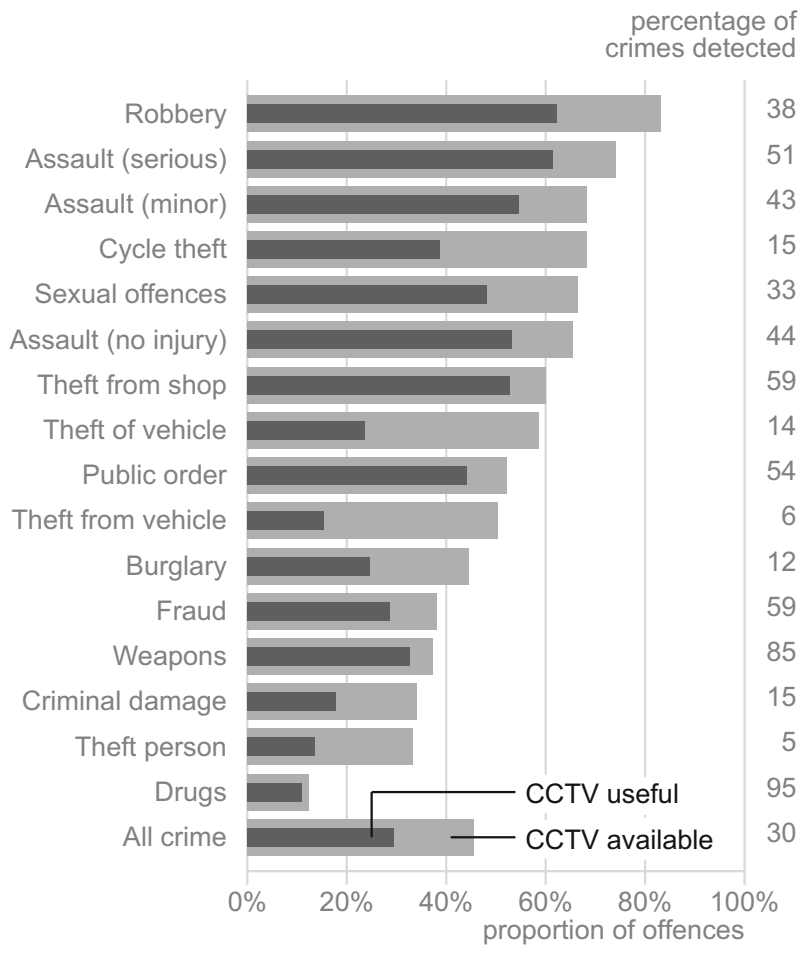

Fig. 2 Proportion of crimes for which CCTV recordings were useful in the investigation

$10.7 \%$ of drug investigations. There was also variation in the proportion of cases where CCTV is useful given that it is available: recordings were often available in cases of thefts from motor vehicles, but are often not useful; in drugs cases, images were rarely available but (when they were) they were almost-always useful. Figure 3 shows the detection rate for offences of each type in which there was or was not useful CCTV evidence. Where the difference is significant at $p<0.001$ using a chi-squared test, the percentage-point difference is shown. ${ }^{2}$

Having useful CCTV evidence is associated with a significantly increased detection rate for all types of crime except drugs, fraud and public order. The largest change is for robbery, where the probability of detecting an offence increases from $8.9 \%$ without useful CCTV to $55.7 \%$ with it. Absent CCTV, detection rates for acquisitive crimes are very low $(<10 \%)$ : only $2 \%$ of theft from the person offences are detected if no CCTV is available. For all types of acquisitive crime (except shop theft) useful CCTV evidence is associated with an increase in detection rates of at least 19 percentage points.

Detection rates in the absence of useful CCTV are higher for violent crimes than for acquisitive crimes. This may be because for violent offences there is always at least one witness (the victim) present at the scene. However, the existence of useful CCTV remains associated with significantly higher detection rates for all types of assault, and for sexual offences.

\footnotetext{
${ }^{2}$ Results for the chi-squared tests are not shown for reasons of space, but are available from the author on request.
} 


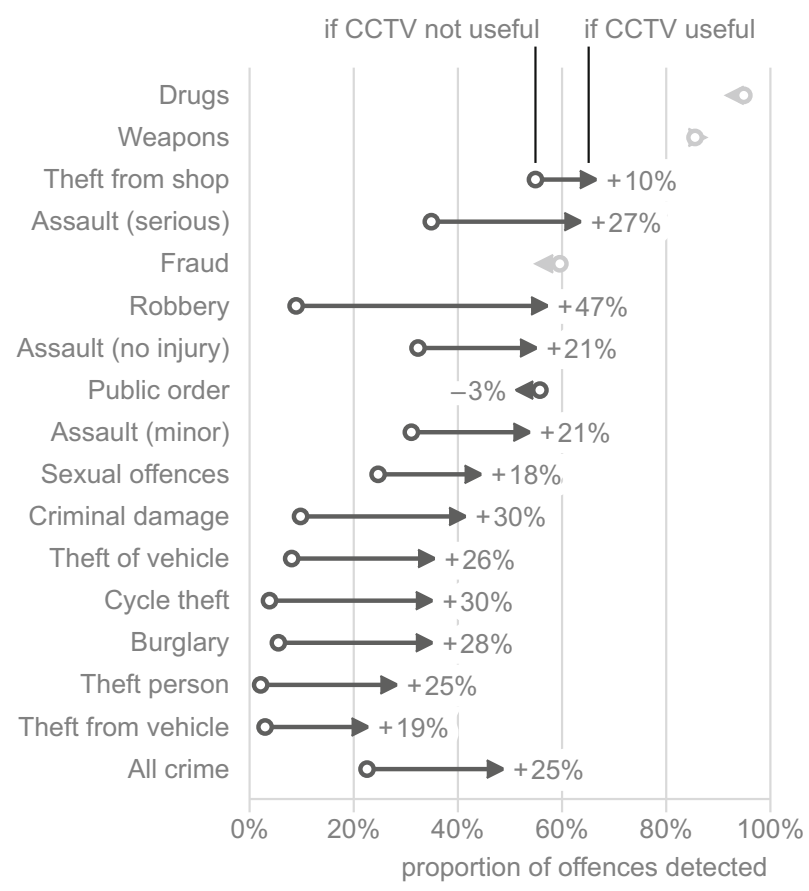

Fig. 3 Probability of crime being solved if CCTV is useful or is not. Percentage difference is shown if significant at $p<0.001$

CCTV is only rarely useful in the investigation of drug or weapon offences (Fig. 2) and the proportion of those offences that are detected is not significantly different when CCTV is or is not available (Fig. 3). This may be because such offences are "intangible" (Chappell and Walsh 1974, p 494): they typically only become known to the police when officers discover them through pro-active tactics such as stop and search. In such circumstances it is unlikely that officers will need CCTV, since the discovery that an offence has occurred also provides the evidence needed to solve it. Put another way, these crimes may be likely to be "self solving", in that the identity of the perpetrator is obvious from an early stage in the investigation (Innes 2007, p 257).

Unlike other types of theft, detection rates for shoplifting are relatively high in the absence of useful CCTV, which is only associated with a modest increase in detection rate. This may suggest that tangibility is not a binary state. Shoplifting offences are known to be substantially under-reported to the police (Home Office 2014), with some shopkeepers often only reporting offences when the thief has been caught, while others report all incidents of which they are aware. As such, shoplifting may be a 'semi-tangible' offence.

No significant association between CCTV usefulness and detection rates was found for fraud offences, but this may be for a different reason. While fraud can take many different forms, it is often an offence where physical action is less important than the offender's intentions. As such, visual evidence such as that provided by CCTV may be less likely to be useful.

Overall it appears that CCTV is frequently useful in investigating a wide range of crimes, although its usefulness varies substantially between crime types. However, it is important to note that it is not possible to establish causation in non-experimental studies such as this. 
The analysis presented so far also does not take into account other variables that may explain the association between CCTV and crime detections. This is the focus of the following sections.

\section{In What Circumstances is CCTV Most Likely to be Useful?}

Based on the results presented in the previous section, five hypotheses were developed about the circumstances in which CCTV is most likely to be (a) available and (b) useful. Given that usefulness is dependent upon availability, the process by which CCTV might be useful was modelled in two stages. The first modelled whether or not a CCTV recording is available and the second modelled whether, if a recording is available, it would be useful or not. Separate binary logistic regressions were run for these two stages, with the same predictors used in both models.

The first hypothesis was that:

$\mathrm{H1}$ : the availability and usefulness of CCTV will depend upon the type of crime being investigated.

This hypothesis was based on the results shown in Figs. 2 and 3, and was included to ensure that variations in availability or usefulness by crime type were controlled for in the model.

Some offences are "aoristic" (Ratcliffe and McCullagh 1998), in that the time at which they occur is not known precisely. Instead, the police typically only know the first and last possible times at which the crime occurred, such as the time a victim left their car unattended and the time at which they returned to find it had been stolen (Ashby and Bowers 2012). The window of opportunity between these two points expresses the period over which the offence could have occurred. A related issue for transport crime is that offences can occur between two locations (such as a bag stolen at an unknown point during a train journey), which Newton et al. (2014) referred to as "interstitial" offences.

If the aoristic window is long, it is possible that the investigating officer will be less likely to request or view CCTV. For example, if a bag is stolen from a car that has been left unattended for a week, the officer may decide not to seize recordings from any cameras in the area because viewing such a large volume of material would be unfeasible. As such it was hypothesised that:

$\mathrm{H} 2$ : the longer the window of opportunity in which a crime could have occurred, the

less likely it will be that CCTV will be available or useful.

In the present data, the aoristic window was less than 10 minutes in $54.0 \%$ of crimes, between 10 minutes and one hour in $19.4 \%$, between 1 and 24 hours in $20.2 \%$ and greater than 24 hours in $6.4 \%$ (median $=6$ minutes, inter-quartile range $=81$ minutes). Since this variable was skewed, it was transformed using a natural logarithm before inclusion in the models.

As discussed above, some types of crime (such as drug possession) are often detected very quickly because they are self solving. This may also be the case where the evidence is overwhelming, or where the suspect rapidly admits the offence. In such circumstances the investigating officer may decide that retrieving CCTV is not necessary, and so any recording will not be useful to the investigation, whether or not if it exists. As such:

H3: CCTV will be less likely to be available or useful in cases that are detected quickly.

To test this hypothesis, offences were categorised according to whether or not they were detected within 72 hours of occurring, as was the case in $9.9 \%$ of crimes. 
The value of CCTV may vary according to the type of location at which the offence occurred. For example, offences occurring at the side of railway lines may be less likely to produce useful CCTV than offences in station ticket halls. To account for this:

H4: The availability and usefulness of CCTV will depend upon the type of place in which the offence occurred.

Offences were categorised (based on a variable recorded by BTP) as occurring either at stations $(37 \%)$, onboard trains (33\% of offences), on or alongside railway lines (7\%), in car parks $(4 \%)$ or at other locations $(19 \%)$.

It is unlikely that all types of crime will be equally important to investigators. One reason why officers may prioritise particular investigations (and therefore be more likely to identify CCTV evidence) is that they involve crimes that are believed to be particularly serious because of their impact on individuals or society. As such:

H5: The more serious that a crime is, the more likely it will be that CCTV will be available and useful.

Operationalising the severity of individual crimes is problematic, since harm comes in many forms. One method that has been discussed in recent literature is to use the severity of punishment expected for a particular offence as a proxy for the harm caused by it (see, for example, Sherman 2013; Ratcliffe 2014). More specifically, sentencing guidelines can be used to determine the number of days in prison likely to be imposed on a first-time offender before any aggravating or mitigating factors are taken into consideration. For the present study, these starting-point sentences were obtained from the Magistrates' Court Sentencing Guidelines (Sentencing Guidelines Council 2008). Following (Sherman et al. 2016), in cases in which the starting point was a community penalty (which is typically specified as a number of hours of, for example, unpaid work) this was converted to days imprisonment based on an eight-hour working day.

Current sentencing guidelines in England and Wales set monetary penalties based on an offender's weekly income (see Sentencing Guidelines Council 2008, p 148), so fines were converted to days of imprisonment based on how long it would have taken for an offender to earn the money to pay the fine. For example, the starting-point sentence for cannabis possession is a fine equal to $100 \%$ of the offender's weekly earnings. Given a 5-day working week, for the purposes of severity this could be converted to 5 days of imprisonment, since that is for how long the offender would have to work to earn that money.

Once a sentence had been converted to days of imprisonment, the variable was scaled to 28-day periods of imprisonment to give a range of values that could be interpreted more easily. The median severity, expressed as the equivalent months in prison, was 1.0 months, with an inter-quartile range of 0.74 months. However, some offences had much higher values: 195 months (16 years) for murder and 130 months (11 years) for rape of a child. Since this variable was skewed, it was transformed using a natural logarithm.

Table 2 shows the results of a binary logistic regression model with the availability of CCTV as the dependant variable, based on 250,665 cases. For each variable, the table shows the estimate $(\beta)$, the standard error (SE) and associated $p$ value, the odds ratio $\left(e^{\beta}\right)$ and the estimated percentage change associated with a one-unit increase in the value of each predictor $\left(e^{\beta}-1\right)$. Table 3 shows the same information for the model used to predict whether CCTV would be useful in cases in which it was available, based on 111,344 cases. $^{3}$

\footnotetext{
${ }^{3}$ To produce a model with a manageable number of variables, different types of assault and of vehicle-related theft were combined into a single category in each case.
} 
Table 2 Predictors of the availability of CCTV Overall model: $\chi^{2}(19)=44,206, p<0.001$, Nagelkerke $R^{2}=0.22, n=250,665$

\begin{tabular}{|c|c|c|c|c|c|}
\hline Intercept & $\begin{array}{l}\beta \\
0.039\end{array}$ & $\begin{array}{l}\text { SE } \\
0.021\end{array}$ & $\begin{array}{l}p \\
0.065\end{array}$ & $e^{\beta}$ & change $(\%)$ \\
\hline \multicolumn{6}{|c|}{ Offence types (compared to miscellaneous other offences) } \\
\hline burglary $^{\mathrm{a}}$ & -0.000 & 0.046 & 0.999 & & \\
\hline criminal damage & 0.149 & 0.026 & $<0.001$ & 1.16 & 16.1 \\
\hline drugs & -1.387 & 0.034 & $<0.001$ & 0.25 & -75.0 \\
\hline fraud & -0.078 & 0.046 & 0.088 & & \\
\hline public order & 0.629 & 0.026 & $<0.001$ & 1.88 & 87.7 \\
\hline robbery & 1.453 & 0.064 & $<0.001$ & 4.28 & 327.6 \\
\hline sexual offences & 0.990 & 0.036 & $<0.001$ & 2.69 & 169.1 \\
\hline theft from shop & 0.515 & 0.032 & $<0.001$ & 1.67 & 67.3 \\
\hline theft from person & -0.069 & 0.022 & 0.002 & 0.93 & -6.7 \\
\hline vehicle/cycle theft & 0.930 & 0.025 & $<0.001$ & 2.53 & 153.5 \\
\hline violence & 0.952 & 0.023 & $<0.001$ & 2.59 & 159.0 \\
\hline weapons & -0.333 & 0.052 & $<0.001$ & 0.72 & -28.4 \\
\hline \multicolumn{6}{|c|}{ Offence circumstances } \\
\hline window (hours) ${ }^{\mathrm{b}}$ & -0.087 & 0.002 & $<0.001$ & 0.92 & -8.3 \\
\hline severity ${ }^{\mathrm{b}}$ & 0.142 & 0.006 & $<0.001$ & 1.15 & 15.3 \\
\hline rapidly detected & -0.708 & 0.017 & $<0.001$ & 0.49 & -50.8 \\
\hline car park ${ }^{\mathrm{c}}$ & -0.297 & 0.023 & $<0.001$ & 0.74 & -25.7 \\
\hline line-side ${ }^{c}$ & -1.932 & 0.025 & $<0.001$ & 0.14 & -85.5 \\
\hline on-train ${ }^{c}$ & -0.977 & 0.013 & $<0.001$ & 0.38 & -62.4 \\
\hline other ${ }^{c}$ & -0.453 & 0.013 & $<0.001$ & 0.64 & -36.5 \\
\hline
\end{tabular}

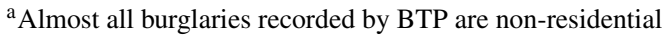

${ }^{\mathrm{b}}$ Natural $\log$

${ }^{\mathrm{c}}$ Compared to offences at stations
}

Overall, compared to a null model with no predictors, the models were significantly better at predicting whether CCTV would be available $\left(\chi^{2}(19)=44,206, p<0.001\right.$, Nagelkerke $\left.R^{2}=0.22\right)$ and-if so-whether it would be useful $\left(\chi^{2}(19)=18,465, p<\right.$ 0.001 , Nagelkerke $R^{2}=0.21$ ). Generalised variance inflation factors (used because some predictors were not binary) were less than 2.4 for all the predictors, suggesting no concerns about multi-collinearity.

As discussed in the previous section, the likelihood of CCTV being both available and useful varied between different types of crime, in line with the prediction of H1. For intangible offences such as the possession and supply of drugs or weapons, CCTV was less likely to be available than for other offences. However, if a recording was available then it was much more likely to be useful. Conversely, recordings were more likely to be available in investigations of thefts of or from vehicles or pedal cycles but (when available) were less likely to be useful. This is interesting because it is for offences in car parks that the crimeprevention benefits of CCTV have been most often demonstrated (Welsh and Farrington 2008). The present finding may be because vehicle and cycle thefts are typically not interstitial, and so it is easy for officers to identify what CCTV recordings to obtain. However, 
Table 3 Predictors of the usefulness of CCTV in cases where it was available. Overall model: $\chi^{2}(19)=$ $18,465, p<0.001$, Nagelkerke $R^{2}=0.21, n=111,344$

\begin{tabular}{|c|c|c|c|c|c|}
\hline Intercept & $\begin{array}{l}\beta \\
0.611\end{array}$ & $\begin{array}{l}\text { SE } \\
0.034\end{array}$ & $\begin{array}{l}p \\
<0.001\end{array}$ & $\begin{array}{l}e^{\beta} \\
1.84\end{array}$ & change $(\%)$ \\
\hline \multicolumn{6}{|c|}{ Offence types (compared to miscellaneous other offences) } \\
\hline burglary & -0.351 & 0.070 & $<0.001$ & 0.70 & -29.6 \\
\hline criminal damage & -0.404 & 0.042 & $<0.001$ & 0.67 & -33.2 \\
\hline drugs & 0.548 & 0.077 & $<0.001$ & 1.73 & 73.1 \\
\hline fraud & 0.351 & 0.086 & $<0.001$ & 1.42 & 42.1 \\
\hline public order & 0.757 & 0.042 & $<0.001$ & 2.13 & 113.3 \\
\hline robbery & 0.259 & 0.071 & $<0.001$ & 1.30 & 29.6 \\
\hline sexual offences & 0.169 & 0.052 & 0.001 & 1.18 & 18.4 \\
\hline theft from shop & 0.869 & 0.056 & $<0.001$ & 2.38 & 138.4 \\
\hline theft from person & -1.047 & 0.035 & $<0.001$ & 0.35 & -64.9 \\
\hline vehicle/cycle theft & -0.139 & 0.037 & $<0.001$ & 0.87 & -13.0 \\
\hline violence & 0.554 & 0.037 & $<0.001$ & 1.74 & 74.0 \\
\hline weapons & 0.993 & 0.124 & $<0.001$ & 2.70 & 169.9 \\
\hline \multicolumn{6}{|c|}{ Offence circumstances } \\
\hline window (hours) ${ }^{\mathrm{a}}$ & -0.098 & 0.003 & $<0.001$ & 0.91 & -9.4 \\
\hline severity $^{\mathrm{a}}$ & 0.002 & 0.009 & 0.822 & & \\
\hline rapidly detected & 1.416 & 0.047 & $<0.001$ & 4.12 & 312.1 \\
\hline car park ${ }^{b}$ & -0.898 & 0.032 & $<0.001$ & 0.41 & -59.3 \\
\hline line-side ${ }^{b}$ & -0.607 & 0.046 & $<0.001$ & 0.54 & -45.5 \\
\hline on-train ${ }^{\mathrm{b}}$ & -0.097 & 0.020 & $<0.001$ & 0.91 & -9.2 \\
\hline other $^{\mathrm{b}}$ & -0.214 & 0.020 & $<0.001$ & 0.81 & -19.3 \\
\hline
\end{tabular}

${ }^{\mathrm{a} N a t u r a l} \log$

${ }^{\mathrm{b}}$ Compared to offences at stations

such offences commonly are aoristic (Ashby and Bowers 2012), so it may be difficult to obtain useful evidence from the recording when it is viewed because of the difficulty of identifying an offender (or even an offence occurring) among many hours of recordings.

The circumstances of the offence were significant predictors of both availability and usefulness. The greater the window of time of which an offence could have occurred, the less likely CCTV was to be available and (when available) to be useful, in accordance with the prediction of $\mathrm{H} 2$.

CCTV was only half as likely to be available in cases that were detected within 3 days of being reported as in those that were not, supporting the prediction of H3. However, in quickly detected cases for which CCTV was available, it was more than four times as likely to be useful as in cases that were not detected quickly, contrary to the prediction.

In accordance with $\mathrm{H} 4$, the type of place in which an offence occurred was a significant predictor of both the availability and usefulness of CCTV. Compared to offences that occurred in stations, recordings were less likely to be available for offences occurring at the side of railway lines or on trains. This almost certainly reflects the distribution of cameras, since CCTV equipment is ubiquitous in stations but not so along the many thousands of 
kilometres of track. Fewer cameras may also mean less overlap between the areas covered by each camera, and so a greater likelihood that an area will be covered only at the periphery of a camera's coverage. This may explain why CCTV is less likely to be useful at the line side even when it is available.

While cameras are becoming common in trains, recordings are often kept for a shorter period than in other types of CCTV system (National Rail CCTV Steering Group 2010), meaning that any delay in requesting images from a train-operating company may mean that on-train images have been overwritten when this would not be the case if the offence had happened in a station. Lack of cameras cannot, however, explain the apparent lower availability of recordings for offences in car parks, since CCTV has long been used in such locations (Poyner and Webb 1987).

As predicted by H5, the more serious an offence, the more likely it was that CCTV would be available to officers. There are several potential reasons for this. Firstly, the operators of CCTV systems may have developed them with their use against serious crimes particularly in mind. For example banks have for many years deployed CCTV systems around automated teller machines (ATMs) to combat robbery of customers (Scott 2001). Secondly, victims may have been more likely to report more-serious offences promptly, making it more likely that recordings would be available to officers. Thirdly, investigating officers may be more likely to invest the time and effort required to obtain and view CCTV in moreserious cases. In any case, where CCTV was available, seriousness was not associated with any change in the likelihood of the recording being useful.

The factors considered in this section suggest that CCTV is more useful in certain circumstances than in others. However, the Nagelkerke $R^{2}$ values for the models $\left(R^{2}=0.22\right.$ for availability and $R^{2}=0.21$ for usefulness) suggest that there is substantial variation in the availability and usefulness of CCTV that is not associated with these factors.

\section{Discussion}

This study produced several potentially useful findings. Firstly, CCTV is frequently useful in the investigation of crime (Fig. 2): recordings were useful in an average of 14,478 BTP investigations a year, including 3,363 assaults, 2,378 vehicle thefts, 562 sexual offences and 273 robberies. The availability of CCTV was associated with substantial increases in the likelihood of most types of offences being solved, with some types of crime very unlikely to be solved when CCTV was not available (Fig. 3).

Secondly, a number of situational factors appear to be associated with the likelihood of CCTV being available and (if so) useful. Recordings were less likely to be available for offences occurring in locations such as on trains or (in particular) at the side of the track (Table 2). CCTV was also less likely to be available if an offence occurred during a long window of opportunity. In cases in which recordings were available, they were less likely to be useful for offences in car parks or involving thefts from the person (Table 3).

Thirdly, it appears that the apparent low usefulness of CCTV reported in previous studies such as the unpublished report produced by the MPS may be a function of CCTV being only infrequently available to some investigators. The present study was able to distinguish between the availability and usefulness of CCTV, in contrast to other work that has not made that distinction, artificially lowering the apparent usefulness of camera systems. Failing to make this distinction is somewhat akin to saying that witness evidence is not helpful in cases where no witnesses were present: true, but not particularly insightful. In short, it may be that if CCTV is not often useful that is because the area in question does not have much CCTV. 
Future studies on this topic should distinguish between the availability and usefulness of CCTV to take this issue into account.

These findings suggest several recommendations for practice. The most important is that if CCTV is made available to investigators then it is likely to be useful in a substantial proportion of cases. At least in the case of railway crime, CCTV appears to be a powerful investigative tool, particularly for more-serious crimes.

This does not mean, however, that place managers should necessarily install CCTV cameras in all types of place, since several other considerations are relevant. Firstly, it may not be possible to replicate the extremely high density of cameras found in many parts of the railway environment. The cost of CCTV systems has reduced over time, but in some cases the investment may not be justified. This is likely to be particularly true where the probability of a crime occurring is low. Lack of data on the location and type of cameras installed meant that this study was not able to consider the costs of CCTV systems, but this is likely to be a relevant consideration for any potential system operator. Installation may be more likely to be justified where the chances of a crime occurring are high (particularly if those crimes are likely to be serious or very frequent), or where CCTV images can be used for multiple purposes. For example, in many railway CCTV systems images are monitored in real time to facilitate crowd management, with any investigative benefit being secondary to their primary purpose of public safety (a diffusion of benefit). In other circumstances it may be that other interventions are likely to be more effective than CCTV in assisting investigations, or preventing crimes from happening in the first place (Ratcliffe 2011, p 21).

The present findings also suggest ways in which investigators could make better use of CCTV. In particular, the findings point to the importance of officers identifying potential sources of CCTV images whenever possible. While officers were more likely to request CCTV in more-serious cases (Table 2), the likelihood of available images being useful was not associated with the degree of seriousness (Table 3). This suggests that if officers are able to seize CCTV in less-serious cases, they are as likely to be useful as in more-serious cases. This accords with previous research by Roman et al. (2008) showing that DNA evidence is valuable in investigations of high-volume, less-serious offences as well as in the investigation of major crime, but that despite this officers often only look for it in serious cases.

There will sometimes be good reasons why CCTV is not requested in a particular case, for example if the police have already obtained overwhelming evidence from other sources. However, it is possible that there remain cases where CCTV could have been useful but in which the investigating officer did not make a request for it. A recent small-scale study of newly installed cameras in two violent-crime hotspots in Stockholm found that investigators requested CCTV recordings in only $20 \%$ of cases in which they were available (Marklund and Holmberg 2015). It is crucial that officers take reasonable and proportionate steps to identify CCTV evidence in every case in which it may be available.

The generalisability of the present results may be limited by the specific characteristics of the railway environment. For example, it is unlikely that many police agencies could achieve widespread CCTV coverage of streets and other public areas to the same degree of saturation that is experienced on railway networks in the UK. Specifications for installing new or upgraded railway CCTV systems in Britain recommend that at least $90 \%$ of areas such as platforms, ticket halls and car parks are covered by cameras (National Rail CCTV Steering Group 2010, p 11). In contrast, many non-railway CCTV systems cover only parts of a local area. CCTV is also likely to be useful less-often for offences that typically take place where cameras are rarely present, such as private dwellings. Even in dwellings, however, there 
have been examples of CCTV providing effective evidence after being installed to protect particularly vulnerable people (e.g. Phillips 1999).

BTP investigators also benefit from most railway cameras being operated by a small number of rail companies. In contrast, local police may have to identify CCTV recordings that could be held by a large number of public and private organisations. Retrieving recordings in such cases may be both more difficult and more time-consuming. In particular, the lack of a national register of CCTV systems may mean that officers investigating an offence in a street may have to speak to every property owner in the area to determine whether they operate a camera system or not.

The data used in this study could not be used to identify whether CCTV made the difference between an offence being detected and not being detected. It is also not possible to determine the nature of causality in the relationships described here without an experimental study. Nevertheless, this study represents the most-detailed published analysis of the value of CCTV in criminal investigations.

Further research in this field would be valuable, particularly given the scarcity of evidence on the use of CCTV for investigation. While the lack of existing research means that there are many potential avenues for investigation, the present results suggest some questions that could usefully be prioritised. Firstly, when CCTV is useful in investigations, what is the mechanism by which it acts? Identifying how CCTV works would be useful if it allowed investigators to prioritise the search for CCTV in certain types of case, or allowed researchers to identify potential barriers to effective use of CCTV that could not be found using the present data. Secondly, it appears that investigators do not request CCTV recordings in some cases in which they could be potentially useful. Why does this happen and what can be done to facilitate the acquisition of CCTV evidence whenever practicable? This information would help to remove any barriers to ensuring the availability of recordings. Thirdly, why is CCTV not useful in cases where it is available? Fourthly, what can be done to minimise the number of cases in which CCTV is available but proves not to be useful? Better understanding of the reasons for this could help to improve the evidence available to investigators.

Acknowledgments Thank you to British Transport Police in particular Ashley Auger, Rhys Gambold, Will Jordan and Vanita Patel for providing the data used in this research. Although relevant BTP officers were given advanced access to the results of this study, control of the content and responsibility for any mistakes lay solely with the author. Thank you also to Manne Gerell of Malmö University for providing a summary translation of a Swedish-language report by Marklund and Holmberg (2015), and to Rebecca Thompson, Andromachi Tseloni and two anonymous reviewers for commen ts on an earlier draft. This research did not receive any specific grant from funding agencies in the public, commercial, or not-for-profit sectors

Open Access This article is distributed under the terms of the Creative Commons Attribution 4.0 International License (http://creativecommons.org/licenses/by/4.0/), which permits unrestricted use, distribution, and reproduction in any medium, provided you give appropriate credit to the original author(s) and the source, provide a link to the Creative Commons license, and indicate if changes were made.

\section{References}

Ashby, M.P.J., \& Bowers, K.J. (2012). A comparison of methods for temporal analysis of aoristic crime. Crime Science, 2(1), doi:10.1186/2193-7680-2-1.

Association of Chief Police Officers (2011). Practice Advice on the Use of CCTV in Criminal Investigations. Wyboston Lakes: National Policing Improvement Agency. 
Bannister, J., Fyfe, N.R., \& Kearns. A (1998). Closed circuit television and the city. In Norris, C., Moran, J., \& Armstrong, G. (Eds.) Surveillance, closed circuit television and social control (pp. 21-39). Aldershot: Ashgate.

Bates, D. (2008, May 6). Billions spent on CCTV have failed to cut crime and led to an 'utter fiasco', says Scotland Yard surveillance chief. Daily Mail.

Bowcott, O. (2008, May 6). CCTV boom has failed to slash crime, say police. The Guardian.

British Transport Police (2016). CCTV. Retrieved April 17, 2016, from http://www.btp.police.uk/advice_and info/how_we_tackle_crime/cctv.aspx.

Bulwa, D., \& Stannard, M.B. (2007, August 17). Is it worth the cost? San Francisco Chronicle.

Chace, R.W. (2001). An overview on the guidelines for closed circuit television (CCTV) for public safety and community policing. Alexandria: VA: Security Industry Association.

Chappell, D., \& Walsh, M. (1974). Receiving stolen property: The need for systematic inquiry into the fencing process. Criminology, 11(4), 484-497. doi:10.1111/j.1745-9125.1974.tb00609.x.

Cockbain, E., Brayley, H., \& Laycock, G. (2011). Exploring internal child sex trafficking networks using social network analysis. Policing, 5(2), 144-57. doi:10.1093/police/par025.

College of Policing (2014). Authorised Professional Practice: Investigation. Retrieved from https://www.app. college.police.uk/app-content/investigations/investigative-strategies/passive-data-generators/.

Cook, T., Hibbitt, S., \& Hill, M. (2016). Blackstone's Crime Investigators' Handbook, 2nd edn. Oxford: Oxford University Press.

Coupe, T., \& Kaur, S. (2005). The Role of Alarms and CCTV in Detecting Non-residential Burglary. Security Journal, 18(2), 53-72. doi:10.1057/palgrave.sj.8340198.

Davenport, J. (2007, September 19). Tens of thousands of CCTV cameras, yet $80 \%$ of crime unsolved. Evening Standard.

Ditton, J., \& Short, E. (1998). Evaluating Scotland's first town centre CCTV scheme. In C. Norris, J. Moran \& G. Armstrong (Eds.) Surveillance, closed circuit television and social control, (pp. 155-173). Aldershot: Ashgate.

Edwards, R. (2008, May 6). Police say CCTV is an 'utter fiasco'. The Telegraph.

Edwards, R. (2009, January 1). Seven of ten murders solved by CCTV. The Telegraph.

Fyfe, N.R., \& Bannister, J. (1996). City watching: closed circuit television surveillance in public spaces. Area, 28(1), 37-46.

Gill, M., \& Spriggs, A. (2005). Assessing the impact of CCTV. Home Office Research Study series. London: Home Office.

Hickley, M. (2009, August 25). CCTV helps solve just one crime per 1,000 as officers fail to use film as evidence. Daily Mail.

Hier, S.P. (2004). Risky space and dangerous faces: urban surveillance, social disorder and CCTV. Social and Legal Studies, 13(4), 541-554. doi:10.1177/0964663904047333.

Home Office. (2011). User guide to Home Office crime statistics. London: Home Office.

Home Office (2014). Crimes Against Businesses Findings 2014. Retrieved from https://www.gov.uk/ government/publications/crime-against-businesses-findings-from-the-2014-commercial-victimisationsurvey/crimes-against-businesses-findings-2014.

Home Office (2016). Retrieved April 18, 2016, from https://www.gov.uk/government/publications/ counting-rules-for-recorded-crime.

Honovich, J. (2008). Is Public CCTV Effective? Retrieved April 15, 2016, from http://ipvm.com/reports/ is-public-cctv-effective.

Information Commissioner's Office (2015). Using the Crime and Taxation Exemptions, Information Commissioner's Office, London. Retrieved from https://ico.org.uk/media/for-organisations/documents/1594/ section-29.pdf.

Innes, M. (2007). Investigation order and major crime inquiries. In Newburn, T., Williamson, T., \& Wright, A. (Eds.) Handbook of Criminal Investigation (pp. 255-276). Cullompton: Devon: Willan.

Instrom Security Consultants (2014). Review of CCTV provision within the Dyfed-Powys Police area. Newport Pagnell: Instrom Security Consultants.

Johnson, M.A. (2008). Smile! More and more, you're on camera. Retrieved April 16, 2016, from http://www. nbcnews.com/id/25355673/ns/us_news/t/smile-more-more-youre-camera/.

Jordan, J. (2004). Beyond Belief?: Police, Rape and Women's Credibility. Criminology and Criminal Justice, $4(1), 29-59$.

Koskela, H. (2003). 'Cam era'- the contemporary urban Panopticon. Surveillance and Society, 1(3), $292-313$.

La Vigne, N.G., Lowry, S.S., Dwyer, A.M., \& Markman, J.A. (2011). Using Public Surveillance Systems for Crime Control and Prevention: a practical guide for law enforcement and their municipal partners. Washington: DC: The Urban Institute.

Levesley, T., \& Martin, A. (2005). Police attitudes to and use of CCTV. Home Office Online Report series. London: Home Office. 
Liberty (2016). CCTV and ANPR. Retrieved April 15, 2016, from https://www.liberty-human-rights.org.uk/ human-rights/privacy/cctv-and-anpr.

London Borough of Hackney (2016). Hackney's improved CCTV control centre officially reopens. Retrieved April 17, 2016, from http://news.hackney.gov.uk/hackneys-improved-cctv-control-centre-officiallyreopens.

Marklund, F., \& Holmberg, S. (2015). Kameraövervakning på Stureplan och Medborgarplatsen. Rapport series. Stockholm: Swedish National Council for Crime Prevention.

Mayhew, P., Clarke, R.V., Burrows, J.N., Hough, J.M., \& Winchester, S.W.C. (1979). Crime in public view. Home Office Research Studies series. London: Home Office.

Merrick, J., \& Duggan, E. (2013). Watch out-fewer CCTV cameras about. Retrieved from http://www.independent.co.uk/news/uk/home-news/watch-out-fewer-cctv-cameras-about-8527928. html.

Metropolitan Police Department. (2007). Closed circuit television (CCTV) 2007 annual report. Washington: DC: Metropolitan Police Department.

National Rail CCTV Steering Group. (2010). National rail and underground closed circuit television (CCTV) guidance document. London: Association of Train Operating Companies.

Newton, A.D., Partridge, H., \& Gill, A. (2014). Above and below: measuring crime risk in and around underground mass transit systems. Crime Science, 3(1), 1-14. doi:10.1186/2193-7680-3-1.

Norris, C., \& Armstrong, G. (1998). Introduction: power and vision. In Norris, C., Moran, J., \& Armstrong, G. (Eds.) Surveillance, Closed Circuit Television and Social Control (pp. 3-18). Aldershot: Ashgate.

Paine, C. (2012). Solvability Factors in Dwelling Burglaries in Thames Valley. Cambridge: Master's thesis, University of Cambridge.

Phillips, C.Painter, K., \& Tilley, N. (Eds.) (1999). A review of CCTV evaluations: crime reduction effects and attitudes towards its use.

Porter, T. (2016). Surveillance Camera Commissioner's IFSEC speech. Retrieved from https://www.gov.uk/ government/speeches/surveillance-camera-commissioners-ifsec-speech.

Poyner, B., \& Webb, B. (1987). Successful Crime Prevention Case Studies. London: The Tavistock Institute of Human Relations.

Ratcliffe, J.H. (2011). Video surveillance of public places. Problem-Oriented Guides for Police Response Guides Series. Washington: DC: Center for Problem-Oriented Policing.

Ratcliffe, J.H. (2014). Towards an index for harm-focused policing. Policing, 9(2), 164-182. doi:10.1093/police/pau032.

Ratcliffe, J.H., \& McCullagh, M.J. (1998). Aoristic crime analysis. International Journal of Geographical Information Science, 12(7), 751-764. doi:10.1080/136588198241644.

Reeve, A. (1998). The panopticisation of shopping: CCTV and leisure consumption. In Norris, C., Moran, J., \& Armstrong, G. (Eds.) Surveillance, closed circuit television and social control (Chap. 4, pp. 69-87). Aldershot: Ashgate.

Roman, J., Reid, S., Reid, J., Chalfin, A., Adams, W., \& Knight, C. (2008). The DNA field experiment: Costeffectiveness analysis of the use of DNA in the investigation of high-volume crimes. Washington: DC: Urban Institute.

Scott, M.S. (2001). Robbery at automated teller machines. Problem-Oriented Guides for Police ProblemSpecific Guides Series. Washington: DC: US Department of Justice.

Sentencing Guidelines Council. (2008). Magistrates' court sentencing guidelines: definitive guideline. Sentencing Guidelines Council: London.

Sheldon, B. (2011). Camera surveillance within the UK: enhancing public safety or a social threat? International Review of Law, Computers and Technology, 25(3), 193-203.

Sherman, L.W. (2013). The rise of evidence-based policing: targeting, testing, and tracking. Crime and Justice, 42(1), 377-451. doi:10.1086/670819.

Sherman, L.W., Neyroud, P., \& Neyroud, E. (2016). The Cambridge Crime Harm Index (CHI): measuring total harm from crime based on sentencing guidelines. Policing, 1-17. doi:10.1093/police/paw003.

Steinhardt, B. (1999). Law enforcement should support privacy laws for public video surveillance. Retrieved April 16, 2016, from https://www.aclu.org/address-video-surveillance-aclus-barry-steinhardt-international-association-police-chiefs.

Stelfox, P. (2009). Criminal investigation: an introduction to principles and practice. Abingdon: Willan.

Taylor, T., \& Gill, G. (2014). CCTV: reflections on its use, abuse and effectiveness. In Gill, M. (Ed.) The handbook of security (Chap. 31, pp. 705-726). Basingstoke: Palgrave Macmillan. doi:10.1007/978-1-349-67284-4 31.

The Scotsman (2008, May 28). CCTV: does it actually work? The Scotsman. 
Tilley, N. (1993). Understanding car parks, crime and CCTV: evaluation lessons from safer cities. Crime Prevention Unit Papers series. London: Home Office.

Webb, B., \& Laycock, G. (1992). Reducing crime on the London Underground: an evaluation of three pilot projects. Crime Prevention Unit Papers series. London: Home Office.

Wells, H.A., Allard, T., \& Wilson, P. (2006). Crime and CCTV in Australia: understanding the relationship. Humanities and Social Sciences Papers series. Gold Goast: Bond University. Retrieved from http:// epublications.bond.edu.au/hsspubs/70/.

Welsh, B.C., \& Farrington, D.P. (2008). Effects of closed circuit television surveillance on crime. Campbell Systematic Reviews, 4 (17). doi:10.4073/csr.2008.17. 